\title{
Human ocular aging and ambient temperature
}

\author{
R. A. WEALE \\ From the Department of Visual Science, Institute of Ophthalmology, Judd Street, London WC1H $9 Q S$
}

SUMmARY A survey of the literature on the incidence of the age of onset of presbyopia in various parts of the world reveals a great deal of variation. At first sight this appears to correlate with geographical latitude, but statistical and epidemiological evidence rules this out in favour of ambient temperature. Indirect evidence suggests that the crystalline lens is located sufficiently near to the surface of the body for this to be a likely explanation.

The power of the human eye to accommodate, that is, to adjust its focus for various distances, diminishes with age. ${ }^{1-3}$ When the resulting disability becomes intolerable, relief is obtained by the use of so-called reading glasses. In principle these are an optical device which increases the apparent distance of the object viewed and also magnifies the resulting retinal image. In temperate countries, such as this, nonshort-sighted people seek such help in the late forties ${ }^{4}$ However, there are reports to suggest that in more southern countries the age $A$ of the onset of presbyopia, that is, eyesight of the aged, occurs significantly earlier. ${ }^{5}$ For example, Rambo and Sangal ${ }^{6}$ mention an age of about 40 for India, a WHO report quotes 36 for the Philippines, the late twenties or early thirties are quoted for Somalia, ${ }^{7}$ etc. A recent study describing the situation in Bolivia ${ }^{8}$ quotes 2 age ranges, namely $48-50$ years for those inhabitants of the country who live in the Andes and some 7 or 8 years earlier for those who inhabit the eastern plain.

The available figures, approximate though they are bound to be, suggest that an environmental factor is at play. Is it geographical latitude? Or illumination? Or temperature?

Let $\mathrm{A}$ be defined whenever possible as the age $\mathrm{A}$ at which the amplitude ${ }^{9}$ of accommodation of the emmetropic, that is normal, eye falls below 3 dioptres (or reading distance). Fig. 1 shows a plot of $\mathrm{A}$ against the geographical latitude $\mathrm{L}$ and the average annual ambient temperature $T .^{10}$ The latter is preferred to an equally plausible alternative variable, namely, the maximum temperature, as the annual average is more precise. There is, however, a high correlation between the 2 , and the present argument does not depend specifically on which of the 2 measures is selected.

Correspondence to Professor R. A. Weale.
The correlation coefficients between $\mathrm{A}$ and $\mathrm{L}$, corrected for $\mathrm{T}$, and also $\mathrm{T}$ corrected for $\mathrm{L}$, are shown in Table 1 together with the levels of significance. Evidently the age of the onset of presbyopia varies inversely with the environmental temperature rather than with the latitude.

Is it a reasonable conclusion when we recall that we are a homothermic species? Surely our eyes are included in the body which manages to maintain a constant temperature. Temperature constancy is, however, maintained only within the core. ${ }^{11}$ the volume of which varies with the temperature. Both in

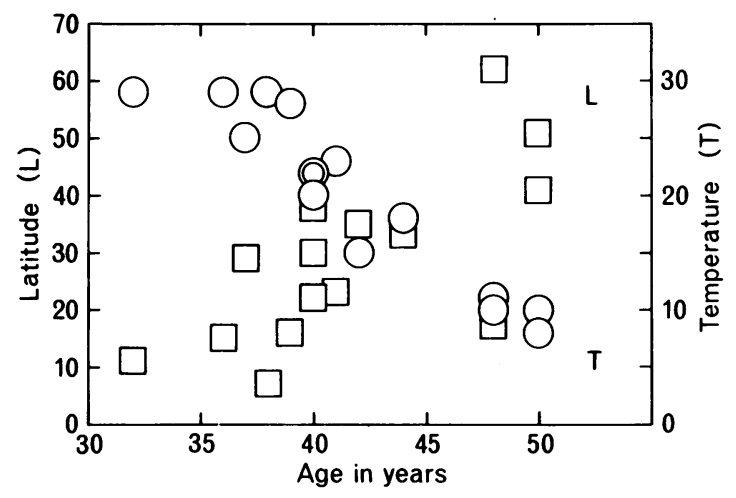

Fig. 1 Age of onset of presbyopia as a function of geographical latitude $L(\square)$ on left scale and mean environmental temperature $T(O)$ on right scale.

Table 1 Correlation data for $A$ versus $L, T$

\begin{tabular}{lll}
\hline & $r$ & $r$ \\
\hline A vs L (controlling for T) & -0.192 & 0.256 \\
A vs T (controlling for L) & -0.887 & 0.1011 \\
\hline
\end{tabular}


the thigh and in the chest ${ }^{12}$ external temperature changes are reflected up to depths of at least 7-8 $\mathrm{mm}$ and, in all probability, deeper than that. The crystalline lens is located largely or wholly within this distance from the surface of the body, and there is therefore good reason for the belief that the temperature of the lens is variable and subject to external influences.

The results obtained in Bolivia ${ }^{8}$ are of particular interest in this connection. The value of $A$ at altitudes between 2500 and $5000 \mathrm{~m}$ is 48 years or more, but in the plain it is about 39 . The mean temperature drop for a $1000 \mathrm{~m}$ rise in altitude ${ }^{13}$ is approximately $6.5^{\circ} \mathrm{C}$, so that, in Bolivia (lat. $17^{\circ} \mathrm{S}$ ), the ambient annual mean at, say, $3000 \mathrm{~m}$ will be in the neighbourhood of $10^{\circ} \mathrm{C}$. Since Sarget ${ }^{8}$ gives $A=48$ years as a minimum at high altitudes, it is certain that the mean value will be higher (cf. Fig. 1).

Another relevant observation is due to Coates, ${ }^{14}$ who found that both coloured and white South Africans manifest presbyopia at similar ages. If there is a significant ethnic difference, it would appear to be submerged by the environment.

Bourlière $^{15}$ has shown that different parts of our bodies age at different rates in different parts of the world. The crystalline lens seems to be exceptional in that the senescence of its function appears to be governed by a single environmental variable.

\section{References}

1 Fisher RF. J Physiol 1973; 228: 765-79.

2 Brückner R. Ophthalmologica 1959; 138: 59-75.

3 Weale RA. Nature 1963; 198: 944-6.

4 Abrams JD, Duke-Elder WS. A System of Ophthalmologv. London: Kimpton, 1970: 5.

5 Weale RA. The Aging Eye. London: Lewis, 1963.

6 Rambo VC. Sangal SP. Am J Ophthalmol 1960; 49: 993-1004.

7 Accardi A. Bull Oculist 1971; 50: 125-30.

8 Sarget JP. An Inst Barraquer 1968; 8: 158-74.

9 Motta MM dos Santos. Rev Bras Oftalmol 1980; 39: 111-25.

10 Fullard H, Darby HC, eds. The Library Atlas. 13th ed. London: Philip. 1978.

11 Ingram DL, Mount LE. Man and Animals in Hot Environments. Berlin. Heidelberg. New York: Springer, 1975.

12 Nielson B. Acta Physiol Scand 1969; suppl 323.

13 Boucher K. Global Climate. London: The English Universities Press. 1975

14 Coates WR. BrJ Physiol Opt 1955; 12: 76-86.

15 Bourlière F. Public Health Papers No. 37. Geneva: World Health Organisation. 1970. 